\title{
Uji Aktivitas Antibakteri Ekstrak Mikroalga Laut Chlorella vulgaris terhadap Bakteri Propionibacterium acnes dan Diformulasikan Sebagai Emulgel
}

\section{The Activity of Marine Microalgae Extract of Chlorella vulgaris Against Propionibacterium acnes and Formulated as Emulgel}

\author{
Aris Suhardiman ${ }^{1 *}$, Sinta Purnamasari ${ }^{1}$, Dewi Kurnia ${ }^{1}$ \\ Jurusan Farmasi, Fakultas Farmasi, Universitas Bhakti Kencana \\ Jalan Soekarno Hatta No. 754 Kecamatan Panyileukan, Bandung, Indonesia 40164 \\ *E-mail: aris.suhardiman@bku.ac.id
}

DOI: https://doi.org/10.26874/jkk.v3i1.49

Received: 11 May 2020, Revised: 31 May 2020, Accepted: 31 May 2020, Online: 31 May 2020

\begin{abstract}
Abstrak
Chlorella vulgaris merupakan salah satu jenis mikroalga yang mempunyai potensi untuk dimanfaatkan sebagai antibakteri. Aktivitas antibakteri tersebut diketahui karena adanya kandungan asam lemak. Penelitian ini bertujuan untuk mengetahui aktivitas antibakteri dari mikroalga $C$. vulgaris terhadap bakteri Propionibacterium acnes. C. vulgaris ditumbuhkan dalam medium Walne dan dikultivasi dengan kondisi suhu ruang $\left( \pm 25-27^{\circ} \mathrm{C}\right)$, fotoperiod 12:12 (gelap:terang), intensitas cahaya 10.000 lux dan aerasi selama $24 \mathrm{jam}$. Ekstraksi $C$. vulgaris dilakukan dengan metode maserasi bertingkat menggunakan pelarut $\mathrm{n}$-heksana, kloroform dan etanol. Uji aktivitas antibakteri dilakukan dengan metode Broth Microdillution pada konsentrasi $65.536 \mu \mathrm{g} / \mathrm{mL}$ hingga diperoleh konsentrasi terkecil 64 $\mu \mathrm{g} / \mathrm{mL}$ dengan pengenceran. Berdasarkan hasil diperoleh nilai KHM pada konsentrasi $8.192 \mu \mathrm{g} / \mathrm{mL}$ dan KBM pada konsentrasi $16.384 \mu \mathrm{g} / \mathrm{mL}$ pada ekstrak n-heksana. Kemudian dilanjutkan dengan uji bioautografi yang menunjukkan senyawa aktif antibakteri berasal dari asam lemak galaktolipid. Aktivitas antibakteri $C$. vulgaris terhadap bakteri $P$. acnes berpotensi untuk dikembangkan dalam bentuk sediaan emulgel. Hasil uji aktivitas sediaan emulgel pada konsentrasi $8 \%$ diperoleh diameter zona hambat 12,63 mm. Berdasarkan hasil yang diperoleh, dapat disimpulkan bahwa ekstrak dan sediaan emulgel dari mikrolaga $C$. vulgaris mempunyai aktivitas antibakteri terhadap bakteri $P$. acnes.
\end{abstract}

Kata Kunci : Antijerawat, Propionibacterium acnes, Chlorella vulgaris, Emulgel

\section{Abstract}

Chlorella vulgaris is a microalgae which is potent to be produced as beneficent healthcare product. $C$. vulgaris has an antibacterial activity due to its fatty acid contents. The purpose of this research was to verify the antibacterial activity of Chlorella vulgaris against Propionibacterium acnes. C. vulgaris is grown in Walne medium and cultivated in room temperature $\left( \pm 25-27^{\circ} \mathrm{C}\right)$, with photoperiod of $12: 12$ (dark:bright), light intensity of 10.000 lux and 24 hours aeration. Multilevel maceration was performed as the extraction method using $\mathrm{n}$-hexane, chloroform and ethanol. The activity test was performed using Broth Microdilution in concentration of $65.536 \mu \mathrm{g} / \mathrm{mL}$ and $64 \mu \mathrm{g} / \mathrm{mL}$ was found to be the smallest concentration by dilution. The result shows the minimum inhibition concentration (MIC) is 8.192 $\mu \mathrm{g} / \mathrm{mL}$ and minimum bactericidal concentration (MBC) is $16.384 \mu \mathrm{g} / \mathrm{mL}$ in extract of $\mathrm{n}$-hexane. Bioautography was performed to identify the antibacterial active compounds which is fatty acid of galactolipid. Antibacterial activity of $C$. vulgaris against $P$. acnes is potential to be developed in emulgel dosage form. The ability of $C$. vulgaris emulgel against $P$. acnes in concentration of $8 \%$ with inhibition zone of $12,63 \mathrm{~mm}$. Based on the results, it is concluded that extract and emulgel of Chlorella vulgaris has antiacne activity against $P$. acnes.

Keywords : Antiacnes, Propionibacterium acnes, Chlorella vulgaris, Emulgel 


\section{Pendahuluan}

Jerawat (acne) merupakan penyakit yang banyak diderita masyarakat terutama remaja. Pengobatan yang lazim digunakan untuk mengatasi jerawat adalah dengan menggunakan antibiotik [1].

Mikroorganisme yang berperan dalam patogenesis jerawat salah satunya adalah Propionibacterium acnes dengan cara memproduksi metabolit yang dapat bereaksi dengan sebum sehingga meningkatkan proses inflamasi [2].

$P$. acnes mengeluarkan enzim hidrolitik yang menyebabkan kerusakan folikel polisebasea dan menghasilkan enzim lipase, hialuronidase, protease, lesitinase, dan neuroamidase yang memegang peranan penting pada proses peradangan. $P$. acnes mengubah asam lemak tak jenuh menjadi asam lemak jenuh yang menyebabkan sebum menjadi padat [2].

Senyawa antibiotik dapat berupa senyawa kimia sintetik atau senyawa alamiah yang berasal dari tanaman obat atau bahan alam bahari yang diperoleh melalui proses pengekstrakan [3].

Mikroalga merupakan sumber antibiotik alamiah yang potensial untuk menghambat bakteri penyebab penyakit pada manusia. Aktivitas antibakteri dari spesies alga sebagai bahan alam bahari memiliki efek samping minimal tetapi memiliki efek terapi yang berpotensi tinggi daripada antibakteri sintesis [4].

Chlorella vulgaris merupakan salah satu jenis mikroalga dari golongan Chlorophyta (alga hijau) yang dapat dimanfaatkan sebagai antibiotik. Telah diketahui aktivitas antibiotik $C$. vulgaris efektif terhadap bakteri Gram positif Staphylococcus aureus, Streptococcus pyogenes dan bakteri Gram negatif Klebsiella pneumonia dan Eschericia coli [5]

Studi penelitian melaporkan bahwa aktivitas antibiotik alga hijau diperoleh dari biomassa, karena adanya kandungan asam lemak dalam organisme mikroalga [4].

Kelompok utama senyawa antibakteri yang ditemukan dalam mikroalga adalah asam lemak, lipid, pigmen, polifenol, karbohidrat, hidrokarbon sederhana dan beberapa turunan lainnya. Selain memiliki aktivitas sebagai antibakteri, mikroalga juga menghasilkan beberapa vitamin penting seperti vitamin $\mathrm{A}, \mathrm{B}_{1}, \mathrm{~B}_{2}, \mathrm{~B}_{6}, \mathrm{~B}_{12}, \mathrm{C}, \mathrm{E}$, nikotinamida, biotin, asam folat, dan asam pantotenat [6].

Berdasarkan hasil penelitian di atas, maka dilakukan upaya untuk pengembangan pembuatan sediaan farmasi dari bahan alam bahari. Sediaan emulgel merupakan salah satu bentuk sediaan farmasi yang cocok untuk digunakan secara topikal. Sediaan emulgel terdiri dari emulsi dan gel berupa sediaan emulsi yang dibuat dengan penambahan basis gel.

Tujuan dari penelitian ini adalah untuk mengetahui aktivitas antibakteri berdasarkan data KHM, KBM ekstrak Chlorella vulgaris terhadap bakteri Propionibacterium acnes dan dilakukan uji Bioautografi serta dibuat sediaan emulgel untuk jerawat.

\section{Metode Penelitian}

Penelitian mengenai senyawa antibakteri $P$. acnes dari alga hijau $C$. vulgaris dan diformulasikan sebagai emulgel untuk jerawat dilakukan dengan metode eksperimental.

Penelitian ini dilakukan dalam beberapa tahapan yaitu aktivasi dan kultivasi mikroalga $C$. vulgaris dalam medium Walne, pemanenan mikroalga menggunakan alat sentrifuga Beckman Coulter Avanti dengan rotor besar JXN-26 pada kecepatan $5.000 \mathrm{rpm}$ selama 10 menit. Supernatan kemudian dipisahkan dan biomassa basah dikumpulkan. Biomassa basah mikroalga dilakukan pengeringan dengan cara Freeze Dry. Selanjutnya mengekstraksi mikroalga $C$. vulgaris dengan metode maserasi bertingkat menggunakan pelarut $\mathrm{n}$-heksana, kloroform dan etanol. Setelah didapatkan tiga ekstrak mikroalga $C$. vulgaris sesuai pelarut, dilakukan uji aktivitas antibakteri dengan metode Broth Microdillution dan menentukan KHM (Konsentrasi Hambat Minimum), KBM (Konsentrasi Bunuh Minimum) dan uji bioautografi. Kemudian memformulasikan ekstrak mikroalga $C$. vulgaris yang memiliki KHM paling baik dan dilakukan uji aktivitas antibakteri sediaan emulgel dengan metode perforasi serta evaluasi emulgel.

\subsection{Alat dan bahan}

Peralatan gelas yang digunakan meliputi gelas ukur (pyrex), gelas kimia (pyrex), botol kaca berkapasitas $1 \mathrm{~L}$, botol gelap, pipa kaca berbentuk L panjang (untuk aerasi) dan pendek (untuk udara keluar botol dan pengambilan sampel), cawan petri, batang pengaduk, pipet tetes, cawan penguap, lampu neon (phillips), mortar, stamper, tabung reaksi, Erlenmeyer (pyrex), krus. Sedangkan untuk peralatan lainnnya yang digunakan adalah sumbat karet, kapas berlemak, kassa, alumunium foil, aerator, selang plastik, mikropipet ukuran $0,5-10 \mu \mathrm{L}, 10-100 \mu \mathrm{L}$ dan 100$1000 \mu \mathrm{L}, \quad$ Haemacytometer (Improved Neurbaeur), Mikroskop, timer, spatel, Autoklaf, 
Inkubator, botol semprot, bunsen, korek api, tip mikro, Neraca Analitik Mettler Toledo, Freeze Dryer, Orbital shaker, Hot Plate, Sentrifuga (Beckman Coulter Avanti JXN-26), Moisture Balance, mikroplate, Salinity Hydrometer, jarum ose, vortex, membran filter berukuran $0,2 \mu \mathrm{m}$, pinset, corong buchner, perforator, jangka sorong.

Bahan utama yang digunakan dalam penelitian ini yaitu biomassa mikroalga $C$. vulgaris yang merupakan kultur murni yang diperoleh dari laboratorium Fakultas Farmasi serta bakteri $P$. acnes (Remel) yang diperoleh dari Laboratorium Mikrobiologi, Institut Teknologi Bandung. Bahan-bahan lain yang digunakan dalam penelitian ini antara lain air laut, aquades (Bratachem), medium Walne, media Mueller Hinton Broth (Oxoid) dan Muller Hinton Agar (Oxoid). Bahan-bahan kimia yang digunakan untuk mengekstraksi Chlorella vulgaris adalah nheksana (Bratachem), kloroform (Bratachem) dan etanol 70\% (Bratachem), DMSO (Bratachem). Bahan-bahan untuk formulasi sediaan emulgel diantaranya HPMC (Bratachem), Parafin cair (Bratachem), Span 80 (Bratachem), Tween 80 (Bratachem), propilen glikol (Bratachem), metil paraben (Merck), propil paraben (Merck), Butil Hidroksi Toluen (Merck), aquadest (Bratachem).

\subsection{Tahapan Penelitian}

Tahap penelitian dilakukan dalam beberapa tahap yaitu.

\section{Kultivasi Mikroalga C. vulgaris}

Kultivasi mikroalga dilakukan setelah 4 hari kultur mikroalga tersebut diaktivasi. Kultivasi dilakukan dengan kondisi yang sama dengan aktivasi menggunakan medium Walne. Kultivasi pada medium Walne dilakukan selama \pm 8 hari dan dilakukan secara aseptik.

\section{Pemanenan Mikroalga C. vulgaris}

Pemanenan mikroalga $C$. vulgaris dilakukan pada hari ke 8 menggunakan alat sentrifuga Beckman Coulter Avanti dengan rotor besar JXN26 pada kecepatan 5.000 rpm selama 10 menit. Supernatan kemudian dipisahkan dan biomassa basah dikumpulkan. Kemudian dilakukan penimbangan menggunakan neraca analitis. Selanjutnya sampel mikroalga dilakukan pengeringan dengan cara Freeze Dry, sehingga didapat biomassa kering dan dilakukan penimbangan kembali menggunakan neraca analitis.

\section{Ekstraksi Mikroalga C. vulgaris}

Ekstraksi dilakukan dengan metode maserasi bertingkat menggunakan pelarut n-heksana, kloroform dan etanol dengan perbandingan biomassa kering mikroalga $C$. vulgaris dan pelarut 1:5 (b/v). Sebanyak $20 \mathrm{~g}$ biomassa kering $C$. vulgaris dimasukan ke dalam erlenmeyer $250 \mathrm{~mL}$ tambahkan pelarut n-heksana sebanyak $100 \mathrm{~mL}$ kemudian disonikasi selama 1 jam. Sampel diaduk menggunakan orbital shaker selama 24 jam pada suhu ruang dengan kecepatan $120 \mathrm{rpm}$. Selanjutnya dilakukan penyaringan menggunakan kertas Whatman No.1 sehingga terpisah antara filtrat dengan residu. Bagian residu dimaserasi kembali hingga 3 kali. Tahap selanjutnya dilakukan dengan proses yang sama pada sampel yang sama (bagian residu) untuk pelarut yang kedua yaitu kloroform dan pelarut ketiga yaitu etanol. Filtrat yang diperoleh dari 3 kali proses maserasi dikumpulkan dan dipekatkan menggunakan rotary evaporator vacuum sehingga diperoleh ekstrak pekat n-heksana, kloroform dan etanol. Ekstrak pekat yang diperoleh dihitung rendemennya.

\section{Uji Aktivitas Antibakteri}

KHM ditentukan dengan menggunakan metode Broth Microdillution. Sebanyak $100 \mu \mathrm{l}$ Mueller Hinton Broth (MHB) steril dimasukkan ke dalam setiap kolom mikroplate. Kolom pertama sebagai kontrol negatif media. Pada kolom ke 12 ditambahkan $100 \mu \mathrm{L}$ ekstrak $C$. vulgaris yang telah dilarutkan dalam DMSO 8\% kemudian dihomogenkan. Dari kolom ke 12, diambil $100 \mu \mathrm{L}$ kemudian dipindahkan ke kolom 11 kemudian dihomogenkan. Pengenceran terus dilakukan sampai kolom ke 3 yang akan memiliki konsentrasi terkecil, dari kolom ke 3 diambil 100 $\mu \mathrm{L}$ dan dibuang. Kemudian pada kolom ke 2 sampai kolom ke 12 ditambahkan $5 \mu 1$ suspensi bakteri $P$. acnes $10^{8} \mathrm{CFU} / \mathrm{mL}$ yang memiliki absorbansi 0,08-0,10 pada panjang gelombang $625 \mathrm{~nm}$. Kolom ke 2 merupakan kontrol positif yang berisi media dan bakteri. Mikroplate diinkubasi pada suhu $37^{\circ} \mathrm{C}$ selama 24 jam dalam inkubator kemudian diamati bagian yang jernih (tidak ada pertumbuhan mikroba). Konsentrasi terkecil dimana tidak terlihat pertumbuhan mikroba ditetapkan sebagai KHM (Konsentrasi Hambat Mininum.

Pengujian dilanjutkan dengan menentukan KBM (Konsentrasi Bunuh Minimum) dengan memilih ekstrak yang memiliki bagian yang jernih dan ditetapkan sebagai KHM kemudian dikultur ulang dengan cara menggoreskan hasil KHM pada 
media padat MHA diinkubasi selama 24 jam pada suhu $37^{\circ} \mathrm{C}$ dalam inkubator dengan posisi cawan petri dibalik. Jika tidak ada pertumbuhan maka disebut KBM.

\section{Uji Bioautografi}

Untuk mendeteksi senyawa aktif yang mempunyai aktivitas sebagai antibakteri digunakan metode bioautografi. Pelat KLT yang telah dielusi di tempelkan pada media MHA steril yang telah diinokulasi dengan $100 \mu \mathrm{L}$ suspensi bakteri $P$. acnes $10^{8} \mathrm{CFU} / \mathrm{mL}$. Diamkan selama 60 menit, diberi tanda bagian bawahnya, lalu plat diangkat kemudian diinkubasi selama 24 jam pada suhu $37^{\circ} \mathrm{C}$ dalam inkubator dengan posisi cawan petri dibalik. Diamati, bila bercak pada kromatogram tersebut yang memiliki aktivitas antibakteri maka dengan difusi akan terbentuk zona bening yang merupakan zona hambat yang memberikan aktivitas antibakteri.

\section{Formulasi Sediaan Emulgel}

Formulasi sediaan emulgel ekstrak mikroalga C. vulgaris dibuat dengan memformulasikan ekstrak yang memiliki aktivitas antibakteri berdasarkan data uji antibakteri dilihat dari KHM, KBM dan uji Bioautografi. Gelling agent yang digunakan yaitu HPMC.

Emulgel dibuat dengan cara mencampurkan emulsi yang telah dibuat ke dalam basis gel sedikit demi sedikit dengan menggunakan homogenizer pengadukan $2000 \mathrm{rpm}$ selama 30 menit atau hingga terbentuk massa emulgel yang homogen.

\section{$3 \quad$ Hasil dan Diskusi}

Kultivasi dilakukan untuk mengumpulkan biomassa sebanyak-banyaknya. Komposisi dari medium akan mempengaruhi biomassa dan kandungan senyawa yang akan dihasilkan oleh mikroalga. Kultivasi dilakukan harus aseptik untuk mencegah timbulnya kontaminan baik berupa virus, bakteri atau organisme lain yang dapat mengganggu pertumbuhan mikroalga. Gambar 1 memperlihatkan wujud biomassa kering hasil freeze dry mikroalga $C$. vulgaris.

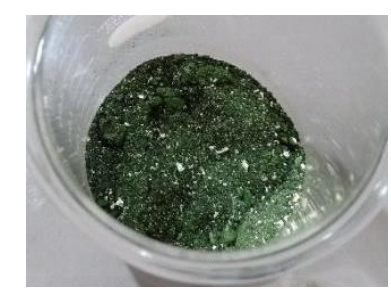

Gambar 1. Biomassa kering hasil freeze dry mikroalga Chlorella vulgaris

Pemanenan dilakukan pada hari ke-8 dengan perhitungan dimulai dari hari ke-0, saat pemanenan dilakukan pengukuran volume kultur dan perhitungan jumlah sel rata-rata. Hal ini dilakukan untuk mengetahui kepadatan biomassa yang diperoleh. Hasil kultivasi dan permanenan diperlihatkan pada Tabel 1.

Tabel 1. Hasil Kultivasi dan Pemanenan

\begin{tabular}{cccc}
\hline $\begin{array}{c}\text { Jumlah Sel } \\
\left.\mathbf{( 1 0}^{6}\right)\end{array}$ & $\begin{array}{c}\text { Volume } \\
\text { Kultur }(\mathbf{m L})\end{array}$ & $\begin{array}{c}\text { Biomassa } \\
\text { Basah (gram) }\end{array}$ & $\begin{array}{c}\text { Biomassa } \\
\text { Kering (gram) }\end{array}$ \\
\hline 21,175 & 5500 & 13,49 & 2,49 \\
13,225 & 9500 & 20,13 & 4,28 \\
14,7 & 13000 & 12,1 & 3,85 \\
21,550 & 7000 & 18,7 & 3,78 \\
20,175 & 8270 & 19,2 & 4,95 \\
10,125 & 15300 & 18,9 & 3,39 \\
20,138 & 18900 & 43,5 & 7,75 \\
21,896 & 19360 & 48,3 & 9,68 \\
\hline
\end{tabular}

Ekstrak pekat yang dihasilkan berwarna hijau kehitaman (hijau pekat). Hal ini diduga karena adanya kandungan klorofil yang dimiliki oleh $C$. vulgaris. Klorofil merupakan pigmen berwarna hijau yang diperlukan dalam proses fotosintesis.
Hasil rendemen ekstrak (Gambar 2 dan Tabel 2) menunjukkan bahwa ekstrak $C$. vulgaris lebih banyak mengandung senyawa polar. Hal ini karena dari hasil pemekatan ekstrak yang diperoleh lebih banyak senyawa yang terlarut 
dalam ekstrak etanol yang merupakan pelarut polar. Tetapi selain mengandung senyawa polar terdapat pula senyawa semi polar dan non polar yang terlarut dalam ekstrak kloroform dan nheksana.

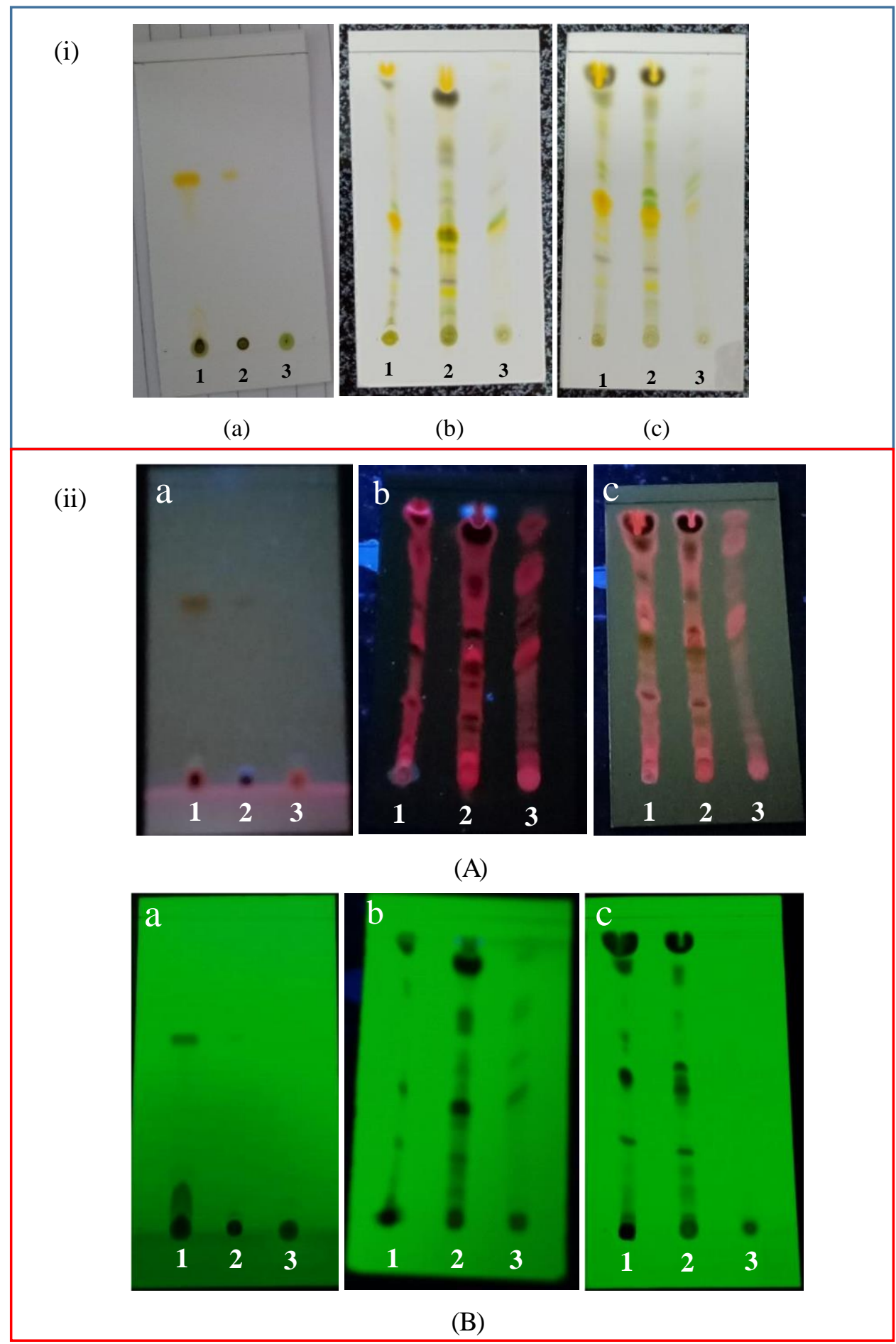

Gambar 2. i) Hasil pemantauan ekstrak secara visual (a) Pengembang non polar; (b) Pengembang semi polar; (c) Pengembang Polar; (1) ekstrak n-heksana; (2) ekstrak kloroform; (3) ekstrak etanol; ii) Hasil pemantauan ekstrak pada (A) UV $365 \mathrm{~nm}$; (B) UV $254 \mathrm{~nm}$; (a) Pengembang non polar; (b) Pengembang semi polar; (c) Pengembang polar; (1) ekstrak nheksana; (2) ekstrak kloroform; (3) ekstrak etanol 
Tabel 2. Hasil Rendemen Ekstrak

\begin{tabular}{ccc}
\hline Pelarut & Bobot $(\mathbf{g})$ & Randemen $(\boldsymbol{\%})$ \\
\hline n-heksana & 0,886 & 4,43 \\
Kloroform & 1,8799 & 9,39 \\
Etanol & 4,4742 & 22,37
\end{tabular}

Pengujian aktivitas antibakteri dilakukan dengan melihat hasil KHM dan KBM ekstrak mikroalga $C$. vulgaris terhadap bakteri $P$. acnes.

Hasil (Tabel 3) menunjukkan bahwa pengujian menggunakan antibakteri pembanding (klindamisin) menghasilkan nilai KHM 128 $\mu \mathrm{g} / \mathrm{mL}$ dengan nilai KBM $256 \mu \mathrm{g} / \mathrm{mL}$. Pengujian selanjutnya dilakukan penentuan nilai KBM yang dilakukan pada semua sampel yang memiliki kejernihan (berdasarkan data absorbansi), kemudian ditanam pada media agar steril. Hasil yang diperoleh yaitu ekstrak n-heksana memiliki aktivitas paling baik dalam menghambat bakteri $P$. acnes pada konsentrasi $8.192 \mu \mathrm{g} / \mathrm{mL}$ dan dapat membunuh bakteri $P$. acnes pada konsentrasi $16.384 \mu \mathrm{g} / \mathrm{mL}$. Sedangkan untuk ekstrak kloroform dan etanol nilai KBM $>32.768 \mu \mathrm{g} / \mathrm{mL}$.
Tabel 3. Hasil Pengujian KHM dan KBM

\begin{tabular}{lcc}
\hline \multicolumn{1}{c}{ Sampel } & $\begin{array}{c}\text { KHM } \\
(\boldsymbol{\mu g} / \mathbf{m L})\end{array}$ & $\begin{array}{c}\text { KBM } \\
(\boldsymbol{\mu g} / \mathbf{m L})\end{array}$ \\
\hline Ekstrak n-heksana & 8.192 & 16.384 \\
Ekstrak kloroform & 16.384 & $>32.768$ \\
Ekstrak etanol & 32.768 & $>32.768$ \\
Klindamisin & 128 & 256 \\
\hline
\end{tabular}

Lipid adalah senyawa organik yang larut pada lemak atau pelarut organik non polar yang umum ditemukan di jaringan tumbuhan. Berdasarkan hasil uji bioautografi (Gambar 3) asam lemak yang terkandung dalam fase nheksana dari mikroalga $C$. vulgaris berperan sebagai antibakteri. Di habitat alami mikroalga, asam lemak dilepaskan untuk melindungi diri atau sebagai mekanisme pertahanan $C$. vulgaris.

Mekanisme asam lemak dari mikroalga $C$. vulgaris belum sepenuhnya diketahui, tetapi ada beberapa bukti efek asam lemak adalah kerusakan pada membran sel bakteri. Aktivitas antibakteri dari asam lemak berdasarkan penghambatan sintesis asam lemak bakteri.
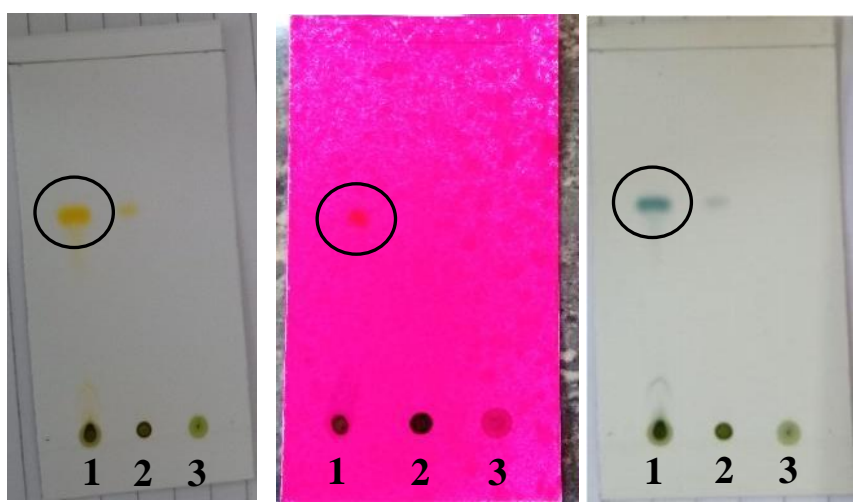

Gambar 3. Hasil uji bioautografi; (a) Sebelum dideteksi; (b) Penampak bercak 0,5\% Rhodamin B dalam etanol; (c) Penampak bercak antron 0,2\% dalam H2SO4 pekat diikuti pemanasan pelat; (1) ekstrak n-heksana; (2) ekstrak kloroform; (3) ekstrak etanol

\section{Kesimpulan}

Dari hasil penelitian yang dilakukan, ekstrak mikroalga $C$. vulgaris memiliki aktivitas antibakteri terhadap bakteri $P$. acnes. Berdasarkan pengujian yang dilakukan diperoleh :

1. Nilai KHM dan KBM terbaik dari aktivitas antibakteri mikroalga $C$. vulgaris adalah pada ekstrak n-heksana terhadap bakteri $P$. acnes yaitu pada konsentrasi $8.192 \mu \mathrm{g} / \mathrm{mL}$ (KHM) dan $16.384 \mu \mathrm{g} / \mathrm{mL}$ (KBM).
2. Senyawa yang bertanggung jawab sebagai antibakteri diduga adalah asam lemak yang merupakan galaktolipid berdasarkan hasil uji bioautografi.

3. Ekstrak terbaik sebagai antibakteri diformulasikan dalam bentuk sediaan emulgel pada konsentrasi $8 \%$ dengan diameter zona hambat $12,63 \mathrm{~mm}$. 


\section{Ucapan Terima Kasih}

Ucapan terima kasih saya ucapkan kepada teman sejawat dosen ibu Dewi Kurnia, M.Si yang telah memberikan arahan dan masukan untuk peneliti dan juga Sinta Purnamasari salah satu mahasiswa yang telah banyak membantu dalam penelitian ini.

\section{Daftar Pustaka}

[1] Daud NS, Suryanti E. Formulasi Emulgel Antijerawat Minyak Nilam (Patchouli oil) Menggunakan Tween 80 dan Span 80 sebagai Pengemulsi dan HPMC sebagai Basis Gel. $J$ Mandala Pharmacon Indones. 2017. 3(02):90-5. http://dx.doi.org/10.35311/jmpi.v3i02.3

[2] Hafsari AR, Cahyanto T, Sujarwo T, Lestari RI. Uji Aktivitas Antibakteri Ekstrak Daun Beluntas (Pluchea indica (L.)Less.) Terhadap Propionibacterium acnes Penyebab Jerawat. In: ISTEK. 9 ed. Fakultas Sains dan Teknologi UIN Sunan Gunung Djati Bandung; 2015. hal. 141-61.
[3] Utami KS. Uji Aktivitas Antibakteri Fraksi Etil Asetat, Kloroform, Petroleum Eter, Dan Nheksana Hasil Hidrolisis Ekstrak Metanol Mikroalga Chlorella sp. Universitas Islam Negeri Malang; 2014.

[4] Syed S, Arasu A, Ponnuswamy I. The Uses of Chlorella Vulgaris as Antimicrobial Agent and as a Diet: the Presence of Bio-active Compounds which Caters the Vitamins, Minerals in General. Int J Bio-Science BioTechnology. $2015 . \quad 7(1): 185-90$. http://dx.doi.org/10.14257/ijbsbt.2015.7.1.19

[5] Ahmed EA. Antimicrobial Activity of Microalgal Extracts Isolated from Baharia oasis. Glob Adv Res J Microbiol. 2016. 5(3):33-41.

[6] Fasya AG, Khamidah U, Amaliyah S, B. SK, Romaidi R. Uji Aktivitas Antibakteri Ekstrak Metanol Mikroalga Chlorella sp. Hasil Kultivasi Dalam Medium Ekstrak Tauge (Met) Pada Tiap Fase Pertumbuhan. Alchemy. 2013. http://dx.doi.org/10.18860/al.v0i0.2889 
Suhardiman, A., et al./J. Kartika Kimia, Mei 2020, 3, (1), 25-32 